\title{
A Girl with Hip Swelling and Convulsion
}

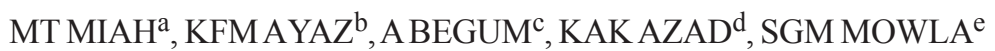

A 15 year old girl presented with gradual swelling and painful movement of both hip for the last 3 years (Figure 1) along with recurrent episodes of generalized tonic clonic seizure for the last 10 months.

On examination patient was ill-looking. There was gross wasting of proximal and distal muscles of both upper and lower limbs. There was diffuse, hard swelling was

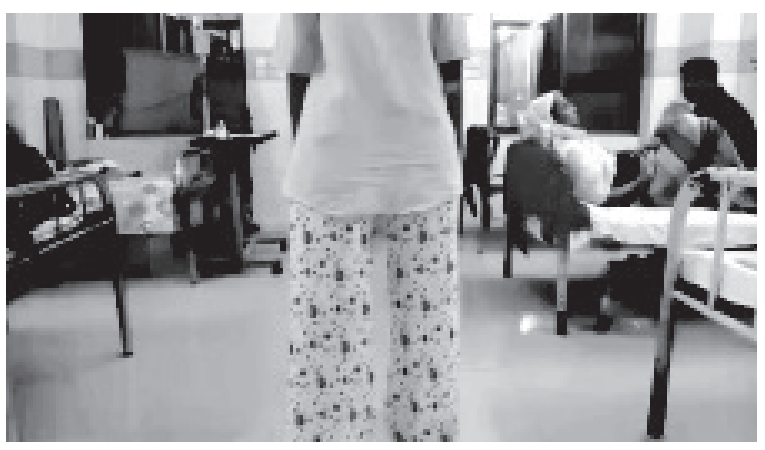

Fig.-1:

present around both hips which were mildly tender on palpation, fixed with underlying bones and soft tissues, overlying skin and temperature were normal. Range of movements in all the joints of upper and lower limbs and spine were within normal limit.

a. Prof. Md. Titu Miah, Professor, Department of Medicine, Dhaka Medical College Hospital, Dhaka

b. Dr. Khan Fariduddin Mohammad Ayaz, Assistant Professor, Department of Medicine, Dhaka Medical College Hospital, Dhaka

c. Dr. Aysha Begum, Indoor Medical Officer, Department of Medicine, Dhaka Medical College Hospital, Dhaka

d. Prof. Khan Abul Kalam Azad, Professor \& Head, Department of Medicine, Dhaka Medical College Hospital, Dhaka

e. Dr. Syed Ghulam Mogni Mowla, Assistant Professor, Department of Medicine, Dhaka Medical College Hospital, Dhaka

Address of Correspondence: Md. Titu Miah, Professor, Department of Medicine, Dhaka Medical College Hospital, Dhaka
Her calcium, albumin, parathyroid hormone level, ALP were normal. Vitamin D3 level was decreased to $9.20 \mathrm{ng} /$ $\mathrm{mL}$, but inorganic phosphate level was high, $6.4 \mathrm{mg} / \mathrm{dL}$. CT scan of the head showed bilateral cerebral calcification (Figure 2).

Xray pelvis AP view showed (Figure 3) amorphous and multilobulated (cloud like) calcification located in

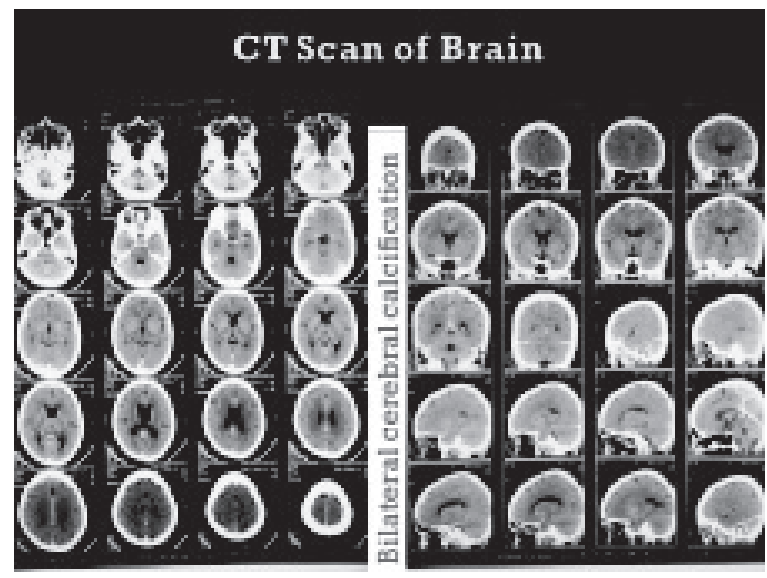

Fig.-2: CT Scan of Brain

periarticular distribution. The patient was diagnosed as a case of Familial Hyperphosphatemic Tumoral Calcinosis.

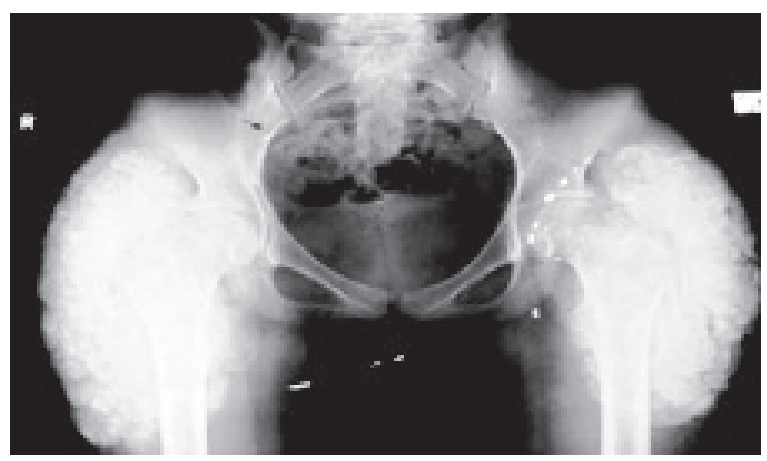

Fig.-3: Xray pelvis AP view 